\title{
Sequence and Hierarchy in Discourse Organization
}

\author{
Pamela Stoll \\ Universidad de Alicante
}

\begin{abstract}
This paper discusses the sequential and hierarchical dimensions of discourse as understood from differing standpoints by conversation analysis and discourse analysis. Section 1 is devoted to the conception of discourse as a linear sequence, which enables the description of the internal structure of exchanges, while section 2 concerns itself with the notion of hierarchy, more suitable for examining the internal structure of moves. In section 3 the functional hierachical discourse model put forward by Roulet et al. (1987) is considered as a synthesis of both approaches supplying a framework for the description of both the linear and hierarchical nature of discourse, monologal as well as dialogal. Section 4 examines one case of implicit dialogism in written monologue, providing a brief illustration of the type of analysis rendered by that discourse model.
\end{abstract}

The analysis of discourse has followed varied paths. Much investigation has been devoted to written discourse, its concepts and methodology being later extended to the study of spoken interactive discourse. On the other hand, conversation analysis, an offshoot from sociology, has applied its own distinctive methods to what it considered the basic type of discourse, conversation taking place in face-to-face interaction. Standpoints and methodology strayed apart, even conflicted with each other (Sacks 1992, Levinson 1983: Chap. 6; Van Rees 1992, Stoll 1994b). One implicit assumption in the debate seems to be that the objects, texts produced by one speaker/writer vs. conversations produced by two or more participants, are so disparate in their organization that they require different approaches. The present paper highlights the presence of two common concepts, those of sequence and hierarchy, in different analyses of monologal and dialogal discourse. 


\section{The linear organization of discourse}

Discourse is produced and interpreted as a sequence of elements. This linear organisation has a prospective dimension, apparent when interlocutors anticipate from the speaker's or writer's current discourse what sort of discourse will come next. This prospective dimension has been studied in monologue, written as well as oral. Producers take into consideration the linguistic expressions they use, as well as textual and situational factors, to anticipate at each relevant point the response of the intended reader or hearer, and structure their monologue following this anticipatory process. On the reception side, the reader or hearer likewise uses linguistic and contextual information to continually formulate and subsequently test hypotheses as to the nature of forthcoming discourse.

As Hoey (1979) and Fillmore (1982), among many others, have studied, prediction operates at word and sentence levels. Nevertheless, the same principle may be extended to discourse, that is, to the actions performed with utterances. This is the approach taken, for instance, by Tadros (1985) in her investigation of economics texts. She views prediction as involving "commitment at one point in the text to the occurrence of another subsequent linguistic event. Thus if there is a signal the reader can predict what the writer will do ...." (6). One example is what she terms "advance labelling," discourse units which indicate the function of subsequent discourse. Thus the utterance

There is one other general conclusion we can draw about the present economic boom.

acts as the announcement of the ensuing act of conclusion.

As for the retrospective dimension of monologal discourse, another student of written monologue, Montgomery, points out that "each succeeding member will adopt one of a restricted set of possible relations with respect to a prior member" (1981: 36). This means that hearers and readers constantly establish links between segments of current discourse and segments of prior discourse. The latter may be assigned a new function so as to adjust its interpretation to incoming information. An example of this is what Montgomery calls "glosses." One type of gloss, the "restate," repeats or reformulates the content of immediately foregoing discourse:

We are not going to put up with your behaviour any longer. In other words, you are fired.

Markers of restate, such as in other words in our example, not only indicate that what comes next is a repetition or reformulation of previous material -a prospective effect-, they also signal that the function of the erlier stretch of discourse is to be reinterpreted. Glosses are a clear exponent of the fact that, when listening or reading, the initial interpretation can be subsequently modified. The assignment of functions to elements of monologue is thus a provisional, dynamic, moment-by-moment affair.

A discourse point of view has also been adopted to investigate the linear organization of dialogue. Labov and Fanshel (1977) argue that the relationship between two utterances by different speakers, as in 
A: Would you like to come for a walk?

B: It's raining.

is not between their propositional contents but between the acts the utterances perform: invitation and rejection. In their study, Labov and Fanshel examine the forward oriented expectations set up by utterances and formulate sequencing rules that limit what acts may come after a specific act in an interaction. Sequencing rules, in other words, establish which acts are available options to the next speaker and present receiver of an act.

A linear conception of discourse is also shared by conversation analysis in its influential concept of adjacency pair and the related notions of sequential implicativeness, conditional relevance and preference organisation. These concepts provide a framework for a description of the prospective character of discourse. Thus an utterance such as

You're coming with us, aren't you?

anticipates an affirmative answer. However, the addressee can ignore the speaker's expectations and preferences and reply with

Who are you?

or even

Go to hell.

Concerned with the different optional sequels to an act, Moeschler (1982) examines the various degrees to which a speaker's reaction fulfils the expectations set up by the previous speaker's act, that is, the degrees of cotextual (in-)adequacy of an act with respect to the previous one. For Moeschler (138ff), in

A: That's a nice book.

B: It seems Peter is in hospital.

speaker B's act is thematically inadequate as it does not take up speaker $\mathrm{A}^{\prime} \mathrm{s}$ theme (the book). In

A: That's a nice book.

B: I haven't read it.

speaker B's act is thematically adequate but propositionally inadequate, as it does not hold a semantic relation with $\mathrm{A}^{\prime}$ 's act. In the next example,

A: That's a nice book.

B: Didn't it bore you? 
B's act is both thematically and propositionally adequate (B's act holds a thematic and semantic relation with $A^{\prime}$ s), but illocutionally inadequate: A's assertion is met with a question, and not with the more adequate evaluation. Finally, in
A: That's a nice book.
B: I liked it too.

\section{A: That's a nice book. \\ B: I think it's lousy.}

B's act is adequate on all three levels (thematic, propositional, and illocutionary). However, only in the former is it also interactionally adequate: a positive evaluation of A's assertion, that is, a confirmation (I liked it too), is more adequate than a negative one, as it indicates B's disposition to conform with $\mathrm{A}^{\prime}$ 's preference for agreement and is thus a face-saving reaction.

The notion of adjacency pair, unlike the speech act based model used by Labov and other discourse analysts, which is only prospective, additionally takes into consideration the retrospective dimension of an utterance in an interaction, that is, the interpretation of previous discourse as shown in the speaker's reaction to it. This interpretation can be explicit, as in
A: I'll get the money back.
B: Don't threaten me!

where B terms A's act a "threat," or implicit, as in
A: It is quite late.
B: OK, I'll drive you home.

where B treats A's move as an indirect request to drive him or her home. Goffman (1981, 35) observes that responses are seen as inspired by a prior speaker, and tell something about their producer's position or alignment in what is occurring. More precisely, says Goffman, "they delimit and articulate just what the 'is occurring' is about, establishing what it is the response refers to." Responses have a "backward reach" (42). Similarly, according to Schegloff $(1992,38)$, "utterances are built to display speakers' understanding; they are made available for coparticipants' inspection to see if they display an adequate understanding of that which they claim to understand."

\section{The hierarchical organization of discourse}

Linear notions such as prediction, retrospection, sequencing rules, adjacency pair, sequential implicativeness and others discussed in the previous section present discourse as composed of elements of a sequence. However, they cannot explain the complexity of longer stretches, written or oral, as they leave out the fact that some discourse elements 
may be intended and/or perceived as more "important" than others, and that this prominence is not necessarily connected with the elements" relative positions in the sequence. Also, it remains unexplained why the same term can be used for a stretch of discourse regardless of its size. For example, a "reply" can consist of one single utterance or a long sequence of utterances. Problems of this kind can only be considered by examining relations between acts within a hierarchical model.

One of the first studies of how discourse elements combine to form larger units is that of Sinclair and Coulthard (1975) on classroom dialogue. They suggest that acts join to form moves, moves to form exchanges and exchanges to form transactions. Transactions in turn make up the speech event, in the case of Sinclair and Coulthard's study, the lesson.

The first aspect of Sinclair and Coulthard's analysis concerns moves, the contribution of only one participant to the interaction. In their examination of the hierarchical structuring of acts within a move, the authors exemplify the way sequential position may affect the function of a component. Thus if the teacher says

What about this one?

the utterance will be interpreted as an elicitation. However, if another component is added to form a larger move, such as in

What about this one? This I think is a super one, Isobel, can you think what it means?

the first act will be "pushed down" to the position of a "starter," whose function is to attract the hearer's attention to what comes next. The starter is subservient to the main act, the elicitation can you think what it means?.

With reference to the same problem of subordination or superordination of acts within a move, Aston (1977: 482 ff.) proposes to identify the relationship (which he terms "interactive") between two components with the answer to the question "What did the addresser do in performing act B which he could not have been said to have done if act $A$ had not previously been performed?" (483). In

John broke his neck. He fell off his bike.

act B, the statement He fell off his bike functions as an explanation of act A, the statement John broke his neck.

The relationship between A and B may be put diagramatically (Aston 486):

A. John broke his neck (statement)

(explanation)

B. He fell off his bike (statement)

The notion of interactivity involves cotextual considerations; the function of act $B$ is defined with respect to another act $A$. If $A$ were absent, $B$ would be interpreted differently. 
Interactive relationships shape the internal structure of a move which, as can be seen in the above example, is hierarchical, and not linear, in character.

Conversation analysts (cf. Heringer 1977; Schegloff 1980; Levinson 1983), though primarily concerned with sequential aspects of interaction, also acknowledge a hierarchical organisation within a move. So-called "pre-sequences" (Excuse me), for example, go before the main act and reduce its possible threat to the addressee's face:

Excuse me. Can you speak a bit louder?

Moves may also begin with "preliminaries" (I would like to ask you something) that indicate the nature or function of the main act:

I would like to ask you something. Is it true that you are having an affair with Bill?

"Preparations" (He's a nice chap) create the conditions for a positive reaction, and act as an argument in favour of the main act of the move:

He's a nice chap. Why don't we invite him too?

The above examples illustrate the ranking within moves, the production by just one speaker or writer. Conversation analysis has also discovered a hierarchical organisation of exchanges, the production of at least two speakers or writers. In the following dialogue,
A: Are you coming to the party?
b: Is Ellen coming too?
a: I think so.
B: I think I'll stay home.

A's first move, a question, establishes the conditional relevance of an informational answer. Speaker B, however, wants to ascertain "if Ellen is coming too" before deciding his or her future course of action. Therefore, the relevant answer to A's initial question is postponed until the exchange $a-b$ has created the conditions for supplying it. The secondary exchange $\mathrm{a}-\mathrm{b}$ creates the conditions for completing the main exchange $\mathrm{A}-\mathrm{B}$.

An argumentative technique frequently applied by speakers when they suspect that their hearer disagrees also shows a hierarchical structure, discussed by Labov and Fanshel (1977: 102ff) as a series of "Socratic questions." Through socratic questions the speaker approaches the problem of the hearer's differing viewpoint by assuring his or her agreement with each single move:

A: You like your work, don't you?

B: Yes.

A: And you love your family, don't you?

B: Yes. 
As B replies affirmatively to each of A's questions, possible arguments for disagreement are eliminated. The newly gained areas of conformity will serve as a basis for continuing the dialogue:

A: And your boss likes the way you work, doesn't he?

B: Yes.

and, finally, for the establishment of $\mathrm{A}^{\prime}$ s point:

A: Then you've nothing to complain about.

B will not find it easy to counter this final conclusion, as he or she has already agreed with the arguments that support it. Atkinson and Drew (1979, chap. 4) have identified the same argumentative strategy in interrogations in court. Roulet et al. (1987) describe it as a hierarchical structure: each single exchange functions as a subordinate argument for A's final move, the main act in the whole sequence.

\section{A synthesis: the functional hierarchical discourse model}

The foregoing observations on linearity and hierarchy in written and spoken monologues and dialogues stem from investigations in discourse and conversation analysis. Roulet et al. (1987) present a synthesis of these insights in their functional hierarchical discourse model. They focus on the two salient types of discursive structures: exchanges and moves.

Exchanges form part of a larger unit, the transaction. The relationship between central and subordinate exchanges is hierarchical, as in the following dialogue
A: Can you cook supper tonight?
b: Why?
a: I don't feel well.
B: I'm going out.

Here, the secondary exchange a-b creates the conditions - speaker B's knowledge of A's motives for the request - for completing the main exchange, request-refusal.

Exchanges are composed of two moves by different speakers. Initiative moves set up the expectation of a reaction; reactive moves look back on a previous one. The relationship between initiatives and reactives is linear, and corresponds to the illocutionary force of speech act theory. Thus moves composing an exchange, such as

A: Would you like to come too?

B: Yes, I'd love to.

can be paraphrased with a performative verb: A's initiative can be termed an "invitation" and B's reactive one an "acceptance."

Moves can be simple, as in 
Would you like to come too?

or complex, composed of a main act (Would you like to come too?) preceded and/or followed by one or more subordinate acts:

It has stopped raining. Would you like to come too? It will do you good.

As discussed in the previous section, the constituents of a complex move are hierarchically linked by interactive relationships. These, as opposed to the linear relationships of illocutionary functions, cannot be paraphrased with performative verbs. In our example, the subordinate act It will do you good can be termed a "justification," which is not a performative expression.

The above outline, however, is not yet complete. Roulet et al. call attention to the fact that classifying discourse by the sole criterion of the number of producers involved is not without difficulties. On the one hand, in some types of dialogal discourse, such as the Socratic dialogue discussed above, exchanges between two speakers acquire a secondary status as arguments for the subsequent conclusion of only one of the speakers. As a result, the dialogue is arrayed under one single perspective:

A: Is it raining?

B: No.

A: Then I'll go for a walk.

The ensuing hierarchical structure is no different from that of a complex monologal discourse, as when a speaker says:

It's not raining.

I'll go for a walk.

The only disparity is that, in the dialogue, the subordinate argument for the main act is the product of two speakers whereas, in the monologue, the argument is produced by just one.

Some monologal discourses, on the other hand, comprise components which make up an exchange and are linked by illocutionary functions. In fact, one common structure in written discourse is when the writer simulates an exchange and expresses not only the question but the answer as well:

Did he suspect anything? No, he did not.

Both components of the exchange could, in an different context, be ascribed to two different speakers. Also, they can be paraphrased with a performative expression, such as "question" and "answer" in our example. The exchange as a whole usually acts as a secondary component of a larger move: 
Did he suspect anything? No, he did not.

So he blindly fell into the trap awaiting him.

the main act being the statement he blindly fell ... . Again, the result is a hierarchical structure, in which an exchange is part of a move. Unlike the dialogue discussed above, however, all components, including the exchange, are originated by one and the same producer.

In order to describe cases such as these, Roulet et al. (1987) propose to complement the formal classification of discourse in terms of the number of producers (dialogal/monologal discourse) with a functional one which distinguishes between monologic and dialogic discourse. In monologic discourse components are linked through interactive relations and have, therefore, the hierarchical structure of a move; in dialogic discourse they are linked through illocutionary functions and have the linear structure of an exchange. To contrast formal as opposed to functional classification implies a distinction between the real producer and the discourse figure of "addresser" (Fr. "énonciateur"). Monologic discourse can be ascribed to one addresser, dialogic discourse to two.

Four possible combinations of formal and functional discourse features may be distinguished, as can be seen in the following table (Roulet et al. 1987: 60):

\begin{tabular}{|l|l|l|}
\hline & one producer & two producers \\
\hline one addresser & $\begin{array}{l}\text { monologal monologic } \\
\text { discourse }\end{array}$ & $\begin{array}{l}\text { dialogal monologic } \\
\text { discourse }\end{array}$ \\
\hline two addressers & $\begin{array}{l}\text { monologal dialogic } \\
\text { discourse }\end{array}$ & $\begin{array}{l}\text { dialogal dialogic } \\
\text { discourse }\end{array}$ \\
\hline
\end{tabular}

Thus there are two cases in which there is a discrepancy between the number of producers and that of addressers: a monologic dialogue (for example, Socratic dialogue) is produced by two speakers but is accountable to only one addresser: the exchanges are part of a higher-ranked move at an abstract level of analysis. A dialogic monologue (for example, the pair question-answer in a monologue), in turn, is the product of only one producer but can be ascribed to two different addressers: the move includes a subordinate exchange at a lower level of analysis. 
4. An application: implicit dialogism in written monologue

The foregoing discussion has clarified the differences, structural and functional, between monologic dialogue and dialogic monologue. Presently I will turn to a specific case of the latter: implicit dialogism in written monologue.

Implicit dialogism may be seen as a dialogue in which the reader's contribution has not been explicitly included. It may take on two different forms. The initiative move of the exchange, which is assigned to the reader, may be left implicit (Stoll 1994a), the discursive structure then being (square brackets indicate the implicit character of a move):

[Reader: initiative move]

Writer: reactive move

Alternatively, it is the reactive move, equally assigned to the reader, which is left unexpressed. Nevertheless there often remain clear indications of the reader's assumed comments or questions. The resulting structure will be:

Writer: initiative move

[Reader: reactive move]

In what follows I will discuss one instance of this second case.

\subsection{The reconstruction of the exchange}

Exchanges whose reactive move is implicit have traditionally been termed rhetorical questions. The writer produces an initiative move and implies not only that a specific answer is due, but that this answer is already known and, therefore, redundant. Rhetorical questions may be seen as an extreme case of anticipation of reader response.

According to conversation analysis, speakers' knowledge of the linear organization of adjacency pairs enables them to predict a second exchange part if the first one is given. Similarly, readers of a written utterance are able to reconstruct the implicit reactive move. As discussed in section 2 above, the conditions of cotextual adequacy establish that a reactive move should be thematically, propositionally and illocutionally adjusted to the initiative. Also, according to the interactional condition, the reactive move should preferably express agreement and conformity with the initiative. Readers, bearing in mind these conditions for a well-formed exchange, are capable of surmising what the reactive move will be.

In the following headline,

Can you handle confrontations?

We show you how (Cosmopolitan, 8.90). 
the writer's initiative - a rhetorical question- opens an implicit exchange to be completed with reactions from a limited set of options: Yes, No or Don't know. The subsequent move helps fix the reader's implied answer:

Writer: Can you handle confrontations?

[Reader: No]

Writer: We show you how

The reader's reply may be no, as in the previous example, or yes, as in:

Getting a lot out of life?

Here's how to put a bit back (Cosmopolitan, 2.91).

Worried because you're staying in?

Don't be (Cosmopolitan, 5.92).

Frequently, the reaction assigned to the reader implies his or her need of the writer's counsel or information:

Are you easily manipulated?

Find out whether you're the type others like to push around (Cosmopolitan, 7.90)

Are you an upper or lower persuader?

Get noticed by those who can help. Here's your plan of action (Cosmopolitan, 5.92)

Where exactly are those wonderful single men?

Our nationwide guide tracks 'em down! (Cosmopolitan, 5.90)

\subsection{The interactive function of the implicit exchange}

The implicit exchange between virtual reader and writer is a linear structure set within the written monologue. It may be seen to function as a subordinate argument for the main act -typically a directive: Here's how to put a bit back, Here's your plan of action, Find out-with which it forms a larger move. The hierarchical structure of this larger move is:

Writer:

Are you easily manipulated?

[Reader:]

[I don't know]

Writer:

Find out whether you're the type others like to push around. 
This type of discourse structure may be considered persuasive. The writer's directives are based on the implied consensus reached with the virtual reader. This reader's collaborative discourse is a constitutive part, albeit implicit, of the writer's monologue. Thereby, discourse exhibits an orientation towards its imagined recipient and strongly anticipates the response it will give rise to.

\section{Conclusion}

This paper has examined the linear and hierachical dimensions of discourse, as conceived by conversation and discourse analysis. The model proposed by Roulet et al. (1987) is considered to synthesize the two approaches and to permit an integrated description of both the linear and hierarchical nature of discourse, monologal as well as dialogal. The analysis of one case of implicit dialogism in written monologue shows a twofold discourse organization: the implied reader's dialogue with the writer - a linear structure - is embedded in the latter's monologue - a hierarchical structure-, and functions as argument for his or her main act.

\section{Works Cited}

Aston, G. "Comprehending Value: Aspects of the Structure of Argumentative Discourse." Studi italiani di linguistica teorica ed applicata IV/3 (1977): 465-509.

Atkinson, Max, and Paul Drew. Order in Court: the Organization of Verbal Interaction in Judicial Settings. London: Macmillan, 1990 (1979).

Fillmore, Charles J. "Ideal Readers and Real Readers." Analyzing Discourse: Text and Talk. Ed. Deborah Tannen. Washington D. C.: Georgetown U P, 1982. 248 -270.

Goffman, Erving. "Replies and Responses." Forms of Talk. Philadelphia: U of Pennsylvania P, 1981. 5-77.

Heringer, James T. "Pre-sequences and Indirect Speech Acts." Southern California Occasional Papers in Linguistics 5 (1977): 169-79.

Hoey, Michael. Signalling in Discourse. Birmingham: U of Birmingham P, 1979.

Labov, W. and D. Fanshel. Therapeutic Discourse: Psychotherapy as conversation. New York: Academic Press, 1977.

Levinson, Stephen. C. Pragmatics. Cambridge: Cambridge U P, 1983.

Moeschler, Jacques. Dire et contredire: pragmatique de la négation et acte de réfutation dans la conversation. Berne, Francfort/M.: Peter Lang, 1982.

Montgomery, Martin. "The Structure of Monologue." Studies in Discourse Analysis. Eds. Malcolm Coulthard and Martin Montgomery. London: Routledge \& Kegan Paul, 1981. 33-39.

Roulet, Eddy, Antoine Auchlin, Jacques Moeschler, C. Rubattel, Marie Schelling. L'articulation du discourse français contemporain. Bern, Francfort s.M., New York, Paris: Peter Lang, 1987.

Sacks, Harvey. 1992 (1984). "Notes on methodology." Structures of Social Action. Studies in Conversation Analysis. Eds. I. Max Atkinson and John Heritage. Cambridge: Cambridge U P. 21-27. 
Schegloff, Emmanuel. “Préliminaries to Préliminaries: ‘Can I ask you a question?”' Sociological Inquiry 50 3/4 (1980): 104-152.

. "On some Questions and Ambiguities in Conversation." Structures of social action. Studies in conversation analysis. Eds. I. Max Atkinson and John Heritage. Cambridge: Cambridge U P, 1992 (1984). 28-52.

Sinclair, John and Malcolm Coulthard. Towards an Analysis of Discourse. The English Used by Teachers and Pupils. London: Oxford U P, 1975.

Stoll, Pamela. Aspectos de la interacción entre escritor y lector. Un estudio pragmáticointerpretativo del dialogismo implícito en la revista femenina británica "Cosmopolitan". Doctoral Thesis. Alicante: Universidad de Alicante, 1994a. (Microfiche).

- "Actos ilocutivos en el discurso monologal escrito: una reflexión metodológica." Paper presented at the AEDEAN Congress. University of Alcalá de Henares, 15-17 Dec. 1994b.

Tadros, Angela. Prediction in Text. Birmingham: U of Birmingham, 1985.

Van Rees, M. A. "The Adequacy of Speech Act Theory for Explaining Conversational Phenomena: A Response to Some Conversation Analytical Critics.” Journal of Pragmatics, 17, 1 (1992): 31-47. 